\title{
AS ESCAVAÇÕES EM MORGANTINA: HISTÓRIA DE UM TRABALHO ARQUEOLÓGICO COMPLETO...OU QUASE COMPLETO
}

\author{
Elaine Farias Veloso Hirata* \\ Maria Beatriz Borba Florenzano*
}

A caracterização geral do sítio arqueológico conhecido até 1956 como Serra Orlando ocorreu já em fins do século XIX, a partir de escavações realizadas por $L$. Papalardo entre os anos de 1882 e 1884. Já desde esta época, ricas residências helenisticas providas de pisos com mosaicos haviam sido identificadas. Em 1912, P. Orsi, eminente arqueólogo siciliano, fez neste sítio algumas trincheiras experimentais, identificando assim mais algumas estruturas arquitetônicas, definidas como de época helenística e romana. Estas e mais as notícias de uma ou outra escavação clandestina realizada no local, permitiam entrever que este deveria ter sido um sítio de alguma importância na Antiguidade.

Partindo destas informações reduzidas e esparsas, a Universidade de Princeton (E.U.A.) deu início em 1955 à primeira temporada de escavações arqueológicas em Serra Orlando. Estas foram realizadas, sob a direção de $\mathrm{R}$. Stillwell e de E. Sjöqvist, sistematicamente até 1963 quando foi anunciada uma pausa a fim de que a documentação material e os registros obtidos em campo pudessem ser organizados de modo a esclarecer melhor os problemas colocados e direcionar com maior eficácia o trabalho seguinte. Deveria ser também uma pausa para que publicações específicas pudessem ser preparadas, as ruinas descobertas pudessem ser consolidadas e para que se pudesse fazer o projeto e as tratativas para a criação de um Museu do sitio ( $P R$ VIII:137).

Em 1966, as escavações foram retomadas mas pararam logo em 1967 devido a enfermidade do Prof. Sjöqvist. Em 1968, foram novamente retomadas, mas como empreendimento conjunto com a Universidade de Illinois e dirigidas por um

(*) Museu de Arqueologia e Etnologia da Universidade de Såo Paulo. dos antigos estudantes da equipe da década de 1950 , o Prof. H. L. Allen. O sítio foi então escavado por cinco anos consecutivos, de 1968 a 1972, quando mais duas novas áreas foram abertas (Childs, 1979:377). Teve início, então, uma pausa bem maior causada ao que tudo indica por problemas financeiros e que durou até 1980 . Nesse ano, com o apoio das Universidades de Virginia e de Princeton, do governo italiano e de muitas outras instituições americanas e italianas, os trabalhos de escavação em Serra Orlando foram mais uma vez retomados, sob a direção de dois outros membros da equipe inicial, os Profs. $M$. Bell III - diretor científico-e W. Childs - diretor administrativo - (Childs, 1979:378). O último relatório é de 1988 e registra as escavações realizadas entre os anos de 1980 e 1985 (PR XII).

Embora de maneira não sistemática, também os italianos escavaram neste sítio, nos anos de 1979 e 1985 (Fiorentini, 1980-81:589-98).

O que mais chama a atenção nestas escavações norte americanas de Morgantina é a forma sistemática como foram realizadas e a procura constante pela "perfeição" tanto na recuperação da documentação quanto na sua apresentação e análise. Outros sítios do mundo grego e romano foram, sem dúvida, escavados e publicados por equipes européias ou americanas com o mesmo rigor e cuidado. Entretanto, apesar dos princípios apregoados em tantos manuais de Arqueologia, não é sempre que encontramos notícias de escavações como as destas de Morgantina. Além disso, o fácil acesso às publicações completas sobre estes trabalhos e a própria importância do sítio para a compreensão do final do período helenístico na Sicilia, fazem deste um exemplo perfeito para a análise e um exemplo fácil de ser acompanhado pelo estudante de Arqueologia que, sem dúvida, terá muito o que aprender com a leitura atenta dos Preliminary Reports. 
Inicialmente, salientamos que estas escavações, no começo, desenvolveram-se afastadas do debate teórico que se deu no campo da Arqueologia, a partir do final da década de 1960. Por isso, não se sente nos primeiros Reports uma preocupação maior em estipular com precisão os objetivos da pesquisa ou as principais hipóteses de trabalho. Mesmo que estes estivessem subjacentes, não se percebe uma necessidade maior em persegui-los a qualquer custo durante o trabalho de campo. Diferentemente do que ocorre com muitas pesquisas que tiveram início na década de setenta e prosseguiram nos anos oitenta que tinham e/ou têm ainda uma preocupação teórico-metodológica muito acentuada o que as orienta para objetivos muito específicos e delimitados. Como exemplo deste tipo de trabalho, podemos mencionar as pesquisas dos New Archaeologists nos E.U.A. ou as dos arqueólogos marxistas italianos (por ex. Blanton, 1978 ou Carandini, 1985). O que fica patente através dos relatórios das escavações de Morgantina, é que se tratava de escavar um sítio inicialmente não identificado com nenhuma cidade conhecida da Antiguidade, mas que pelas notícias anteriores parecia ter sido um local de certa importância. Tratava-se, de, modestamente, escavá-lo sistematicamente, recolhendo e registrando toda a documentação material que fosse posta à luz, a fim de esclarecer a sua história. (Childs, 1979:379). Deve-se mencionar também o objetivo didático destas escavações e o empenho em formar arqueólogos de primeira linha que movia os Profs. Stillwell e Sjöqvist (Childs, 1979:377).

Quanto a este ponto, abrimos aqui um pequeno parêntese pois é preciso render um tributo a estes dois professores tão persistentes e pelas mãos de quem formaram-se, em Morgantina, muitos arqueólogos que contribuiram e continuam a contribuir muito, seja como estudiosos de arqueologia clássica seja como professores em renomadas universidades. Basta citar os nomes de Malcolm Bell, Ross Holloway, Leslie Sheers, Mario del Chiaro, Donald White, Kenam Erim, William Childs, entre tantos outros.

A descoberta, já desde a segunda temporada de escavação, de que Serra Orlando era Morgantina e a riqueza do material recuperado deve ter, sem dúvida, indicado aos escavadores que a pesquisa prometia ser muito mais extensa do que talvez previssem de início. A utilização das fontes escritas sobre a cidade de Morgantina permitiriam, com efeito, um redirecionamento da pesquisa e uma delimitação melhor dos objetivos da escavação. Ao mesmo tempo que os textos antigos poderiam esclarecer os fatos e dar sentido ao documento material, poderiam contradizê-lo, tomando a pesquisa mais complexa e desafiadora. Efetivamente, a articulação entre fonte textual $\mathrm{e}$ fonte material pôde ser trabalhada a todo instante pelos escavadores de Morgantina, levando-os, por exemplo, a identificarem estratos de destruição do séc. $V$ com a tomada da cidade por Ducétio em 459 a.C. (Tucídides, IV, 65, 1) e os do séc. III com as vicissitudes da Segunda Guerra Púnica entre 214 e 211 a.C. (T.Lívio, XXVI, 21, 17). A análise conjunta dos dois tipos de fontes permitiram também - para citar mais um exemplo importante entre tantos - enriquecer toda a discussão que já existia previamente sobre a data e a função da criação do sistema monetário romano, registrado pelas fontes escritas de um modo (Plínio, H.N., XXXIII, 13, 42-47) e de outro pelo contexto arqueológico de Morgantina (Buttrey, 1965). A pesquisa arqueológica pôde ainda ser redirecionada no sentido de se insistir na procura de vestígios pré-históricos e arcaicos já que a fonte textual aponta para uma fundação remota da cidade (Estr., VI, 1, 6 e 2,4) e ainda no sentido da busca de elementos referentes ao contato grego-indigena, possibilidade também referida pelas fontes (Diod. Sic. II,78,5).

Sob um outro aspecto, percebe-se pelos relatórios das escavações, que o advento da New Archaeology em fins dos anos sessenta e todo o debate teórico que se seguiu e que perdura até hoje na Arqueologia, não passou desapercebido à equipe de escavação de Morgantina. À medida que as escavações foram prosseguindo, novos métodos foram aos poucos adaptados à realidade do trabalho de campo, nova aparelhagem foi sendo empregada e a interdisciplinaridade passou a atender mais intensamente novas necessidades criadas. Nos dois últimos relatórios, nota-se uma preocupação em explicar de antemão os objetivos do trabalho de cada temporada. Percebe-se igualmente um cuidado em reescavar certas áreas com a finalidade de completar os dados e de dar uma interpretação mais "objetiva" ou "cientifica" sobre problemas que nas etapas anteriores pareciam praticamente solucionados. 
Além do caráter sistemático destas escavações, é preciso salientar o caráter também sistemático das publicações. Valendo-se do American Journal of Archaeology como veiculo de divulgação, os diretores dos trabalhos de campo, publicaram anualmente os relatórios de escavações, denominados Preliminary Reports.

Nestes textos são elencadas e discutidas - preliminarmente - as principais descobertas da temporada; são aventadas as primeiras interpretações e as conclusões gerais elaboradas vão mostrando ao público o caminho e as hipóteses de trabalho que guiarão as atividades da temporada seguinte. Artigos esporádicos, temáticos também foram publicados (veja-se aqueles citados na Bibliografia). A importância destas publicações reside justamente no fato de que os dados foram colocados à disposição do público especializado regularmente, ao contrário de muitos relatórios e anotações de campo que acabam ficando trancados a sete chaves ou que circulam apenas entre um grupo reduzido de pessoas. Esta atitude dos arqueólogos americanos propiciou a seu tempo o debate e a contribuição de outros pesquisadores, fato evidenciado pelas discussões que surgiram sobre a inscrição

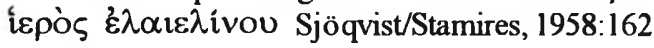
e Smith, 1959:183).

Mas o programa de publicações das escavações de Morgantina é ainda mais ambicioso. Inclui igualmente uma série - Morgantina Studies - que apresenta sob forma de monografia, estudos sobre tipos especificos de documentação material. O vol. I, publicado em 1984 trata das terracotas e o vol. II das moedas (vide mais adiante comentário específico de cada um). A série deve ainda continuar, apresentando as análises mais aprofundadas de materiais diversos como as fortificações, a cerâmica, os vestigios arquitetônicos, os planos urbanísticos da cidade, os celeiros, as necrópoles, os santuários, as inscrições, os vestígios de fauna, os vidros, etc., cada um deles a cargo de um ou dois especialistas (PR XII:314).

Outro projeto no interior desta programação maior, foi o de criação de um Museu do Sítio Arqueológico de Morgantina, como aliás já mencionamos acima. Anunciado no PR VIII, (1963:137), foi formalmente aberto ao público na cidade de Aidone, próxima ao sítio, em 1984 $(P R X I I: 340)$. É importante que se ressalte a preocupação destes arqueológos com a divul- gação dos resultados de seus trabalhos junto à população local, através da criação de um museu regional. Neste sentido, a Superintendência de Antiguidades da Sicília meridional e central promoveu a restauração de um antigo convento da ordem dos Capuchinhos, datado do séc. XVII, instalando ai o museu; na igreja anexa ao edificio, decorada no estilo rococó siciliano, são realizadas conferências e eventos públicos. Embora hoje seja relativamente difundida a tendência à regionalização dos museus, fornecendo às populações das áreas escavadas um contato mais estreito com o trabalho arqueológico, o mesmo não se pode afirmar em relação ao que ocorria, no início dos anos 60. Merece, portanto, destaque o empenho dos arqueológos de Princeton, viabilizando este projeto.

Nesta nossa apresentação geral da programação de pesquisas em Morgantina, devemos chamar a atenção ainda para o longo período de tempo transcorrido desde o início dos trabalhos em 1955 e a última publicação a que tivemos acesso que é de 1992. Durante estes anos todos, muitas devem ter sido as dificuldades: desde as financeiras - assinaladas por Childs (1979:377) - até as organizacionais, relacionadas com formação de equipes, com o relacionamento com as autoridades italianas, com a concessão dos direitos científicos sobre o material... dificuldades tão bem conhecidas dos arqueólogos. O que fica entretanto, depois de uma leitura atenta dos Preliminary Reports, dos dois livros da série e dos outros artigos, é que estes problemas foram contornados com habilidade e que, apesar de passar tantos anos, não interferiram em absoluto seja na regularidade seja na qualidade das atividades e das publicações.

Além da problemática que diz respeito a como se desenvolveu este programa de pesquisa arqueológica em Morgantina, merece comentário - mesmo que rapidamente - a natureza das descobertas arqueológicas que ali ocorreram. Sob este ponto de vista, não é apenas a história de uma única cidade que está em jogo, mas as possibilidades de comparação que a recuperação meticulosa do documento material autoriza Comparação que permite esclarecer a função, a proveniência e a importância de outros documentos similares, que não puderam ser recolhidos com a mesma precisão e que estão hoje conservados em coleções particulares ou em museus pelo mundo afora. Comparação que permite ainda a sintese dos acontecimentos em 
periodos fundamentais para a compreensão da história de uma região inteira. É como se se encontrasse uma peça articuladora de um quebra cabeças o qual adquire então todo o seu significado, ou quase todo.

Assim, o cuidado com que foram realizadas as escavações de Morgantina permitiu não apenas que se elucidasse o papel desempenhado por essa cidade ao longo de sua história - em épocas, intermediária entre os centros gregos ou entre os gregos e os indígenas; em outras, receptadora e distribuidora da produção agrícola de toda uma região -, como também permitiu que se esclarecessem fatos importantes sobre temas muito específicos, próprios do mundo grego. Dentre estes merecem destaque as técnicas de construção e os projetos arquitetônicos e urbanísticos, os cultos, principalmente os de Deméter e de Perséfone, os rituais funerários, os contatos com o leste mediterrâneo na Idade do Bronze, os contatos entre gregos e indigenas no período arcaico, a introdução do sistema monetário romano, etc. etc..

\section{As escavações de Morgantina:}

\section{história de uma colônia grega da Sicilia}

A trajetória de Morgantina, núcleo urbano helenizado cuja ocupação original remonta à Idade do Bronze na Sicília, vem sendo progressivamente desvendada pelo trabalho arqueológico sistemático que a Universidade de Princeton desenvolve na área desde 1955, como foi visto acima.

Para Diodoro Sículo, Morgantina era, por volta da metade do séc.V a.C., uma "axiologos polis " ou seja, uma cidade digna de consideração, afirmativa que encontra respaldo na documentação arqueológica e nas fontes escritas, que relatam a intensa movimentação política por que passou a Sicília.

O sítio da antiga Morgantina situa-se em uma área de topografia acidentada, conhecida hoje como Serra Orlando, província de Enna (Fig. 1). Trata-se de um núcleo interiorano a leste de Catânia e Leonte, colônias de onde, provavelmente teriam origem os fundadores da cidade. Ocupa um espinhaço de $3 \mathrm{~km}$ de extensão localizado entre os rios Gornalunga - que deságua em Catânia - e Gelas que corre para o sul em direção à cidade do mesmo nome.
Situada, portanto, em uma área estratégica, Morgantina pôde dominar rotas que ligavam Gela, Agrigento e Siracusa com a costa setentrional da ilha, configurando-se como centro de comércio e, quando necessário, uma útil base para operações militares.

Alongando-se segundo um alinhamento SO$\mathrm{NE}$, em uma continua sucessão de colinas e depressões, Morgantina apresenta linhas sinuosas que os muros defensivos buscaram seguir, criando um traçado irregular, nem sempre definidor dos exatos limites da cidade. No ponto mais alto do estabelecimento, situado ao norte, em uma colina hoje denominada "Cittadella", foram recuperados os mais antigos vestígios arqueológicos datados do período do Bronze.

O nome "Cittadella" é documentado pelo menos desde o séc. XVI, quando aparece assinalado no mapa Mercator da Sicilia (Mercator: 1589, tab. 15). Esta denominação é provavelmente muito mais antiga e indicativa do seu papel como cidadela da cidade. A "Cittadella" é uma pequena colina cônica situada $600 \mathrm{~m}$ acima do nivel do mar e a $300 \mathrm{~m}$ dos vales vizinhos; para sudoeste e nordeste, acha-se rodeada por platôs suaves que terminam abruptamente em direção aos vales abaixo.

De acordo com Estrabão (VI, 1,6 e 2,4) o estabelecimento originário teria sido ocupado, por volta de 1.200 a.C. pelos Morgetes, população oriunda da Calábria e que, pressionada pelos enótrios, teria abandonado Régio e cruzado o estreito de Messina na busca de terras. Morges, o herói epônimo dos Morgetes, inclui-se no mesmo grupo de personagens miticos fundadores de cidades tal como Aeolus, o colonizador das Ilhas Eólicas e fundador de Lipara. Em vários relatos mitológicos reivindica-se para povoadores itálicos a fundação de cidades na Sicília usando como rota de passagem as Ilhas Eólicas.

As evidências arqueológicas relativas a áreas de enterramentos documentam a penetração dos colonos gregos na região e o seu progressivo estabelecimento na "Cittadella" a partir do início do séc. VI a.C.

Assim, a vida urbana se iniciaria tardiamente em Morgantina. Por volta do segundo quartel do séc. VI a.C., colonos oriundos das póleis calcídicas da Sicilia oriental - segundo E. Sjöquist, Catânia ou Leonte - teriam aí se estabelecido atraídos pelas terras propícias ao 


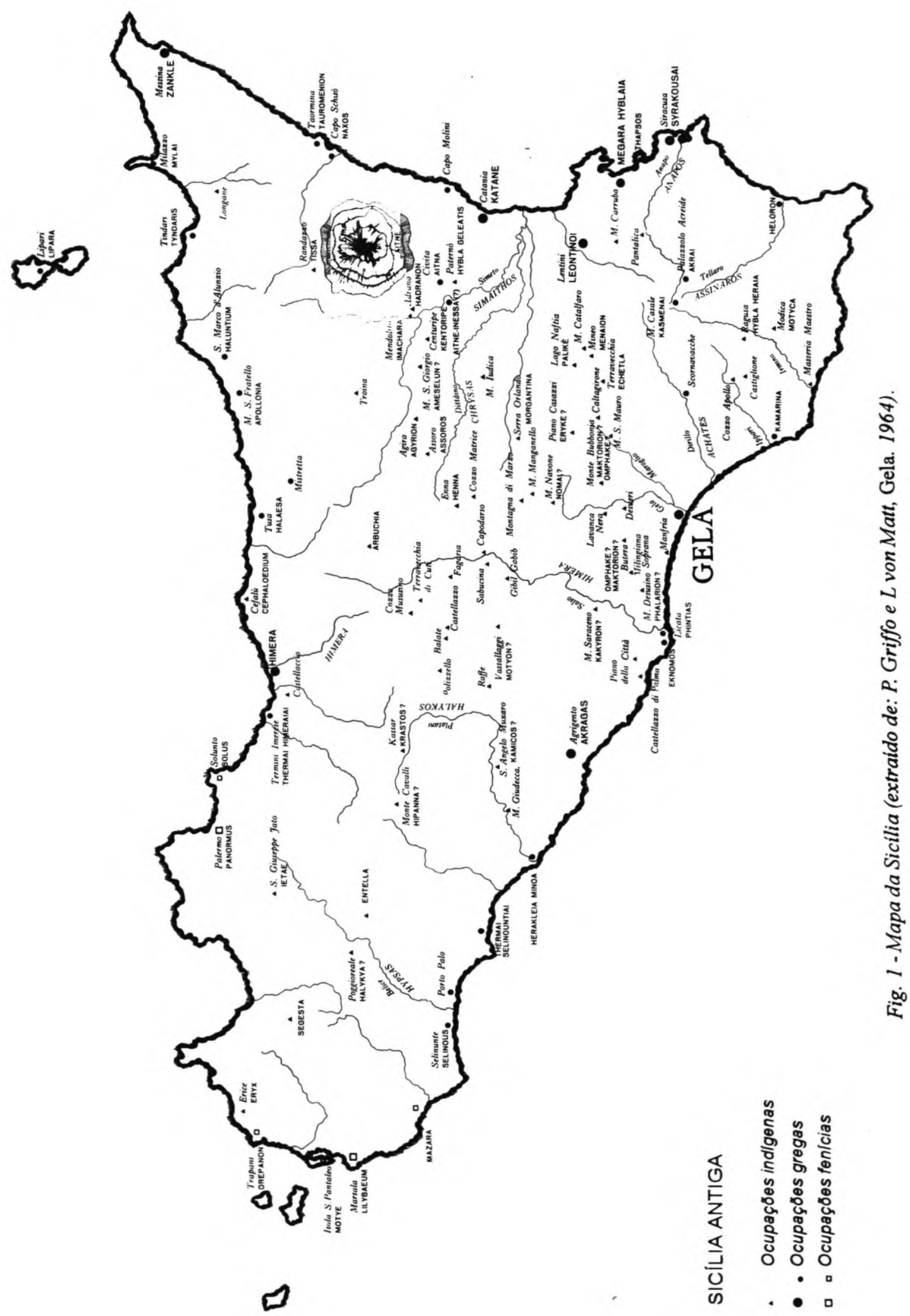


cultivo do trigo, do vale do Gornalunga.

A antiga ocupação sícula na "Cittadella" parece ter convivido pacificamente com os recémchegados. A ausência de implantação de um plano urbanistico ortogonal logo ao início da ocupação grega tem levado os especialistas a negar ter havido um ato oficial e formal de fundação, mas sim um processo gradual promovido por grupos isolados de agricultores sem o patrocínio institucional de uma pólis.

Durante o final do séc. VI a.C. a cidade cresceu, foram contruídos naiskoi com revestimento em terracotas pintadas e tumbas em câmara nas ladeiras da "Cittadella". Os enterramentos múltiplos continham cerâmica e terracotas importadas da Grécia metropolitana e do Egeu, bem como exemplares de vasilhas do Geométrico tardio produzidas pelos ceramistas locais.

As tumbas "em câmaras" com enterramentos familiares ou talvez clânicos, constituem um traço marcante da cultura sícula e a sua permanência poderia sugerir uma presença indigena forte o que, no entanto, é questionável tendo em vista a predominância de artefatos de conotação grega, desde $o$ inicio da fundação.

Ao final do séc.VI a área da "Cittadella" já não comportava um tal crescimento do núcleo urbano o que determinou uma expansão para o platô vizinho de Serra Orlando, documentada pela construção de um naiskos e provavelmente algumas habitações. Era o prenúncio da total transferência, logo a seguir. A análise do material cerâmico dos mais antigos niveis de ocupação habitacional em Serra Orlando remetem a 450 a.C. o início deste processo.

Já no início do séc. $V$ a.C. a conjuntura política instável da Sicilia refletiu-se na até então isolada Morgantina. A estratégia expansionista dos Deinomênidas - especialmente Hipócrates e Gélon, tiranos de Gela - não haveria de poupar Morgantina, situada, como já foi apontado, em importante entroncamento de rotas de comunicação entre as porções sul e este da Sicilia. Os vestígios de uma construção identificada como um forte e datada do extremo final do séc. VI a.C. constituem um indicativo da situação perigosa pressentida pelos habitantes da cidade.

Os níveis de destruição atestados pelos registros arqueológicos no início do séc.V a.C. têm sido associados a este conturbado periodo de constantes incursões militares na disputa pelo controle de Siracusa. É provável que, a partir de 490 a.C., Morgantina tenha estado, como muitas outras cidades da área, sob o domínio gelosiracusano. Artefatos deste período,como as estatuetas de terracota, atestam a presença siracusana na adoção de tipos iconográficos diretamente relacionados a esta cidade.

Em 459 a.C., o líder sículo Ducétio toma Morgantina em um desesperado esforço para impedir o avanço grego na Sicília central. Esta captura encerra a primeira fase de existência da cidade e provoca um quase abandono: após a metade do século a população escasseia, as tumbas "em câmara" desaparecem. Morgantina sobrevive apenas por razões estratégicas e não mais como um centro urbano populoso.

Tucídides (IV, 65,1) relata que por ocasião do Congresso de Gela (424 a.C.) Morgantina foi "dada" por Siracusa a Camarina em troca de determinada soma. A intenção teria sido estabelecer uma zona neutra entre as cidades rivais de Agrigento e Siracusa.

A destruição de Camarina pelos cartagineses em 405 propiciaria uma efêmera liberdade à cidade que, logo em 396 seria capturada por Dionisio de Siracusa, devendo permanecer na esfera de influência desta cidade pelos próximos dois séculos (Diod. Síc. XIV, 78, 7).

Pouco depois de 396 a.C. Morgantina cunhou um tetradracma inspirado fielmente nos didracmas siracusanos de Euaineto (Rizzo, 1946: 2687, 6, pl. LX). Esta moeda constitui um registro emblemático do relacionamento político que se estabeleceu entre as duas cidades.

A implantação de um plano ortogonal no traçado urbanístico do platô de Serra Orlando pode ser situada logo após o Congresso de Gela ou talvez no reinado de Dionísio e consolida a transferência total do núcleo urbano da "Cittadella" para a nova área.

A nova configuração urbanística apresenta uma vasta área monumental central que engloba a ágora, o teatro, vários edifícios públicos e uma área de habitações.

A década 340-330 a.C. representa, para Morgantina, uma intensa retomada de crescimento, em sintonia com a prosperidade econômica, repovoamento e pacificação empreendidos por Timoleonte por toda a Sicília. Sjöqvist (PR IV, pl. 36, fig. 37) aponta a construção do "Santuário Norte" e dos muros protetores da área urbana 
de Morgantina desde as épocas mais recuadas. Assim, E. Sjöqvist (1962b:52-68) descreve as mais antigas fases de ocupação do sítio, a partir do exame de evidências provenientes da área da "Cittadella" e de uma pequena extensão no platô de Serra Orlando. Nesta região foi encontrado abundante material e vestígios de cabanas datadas dos sécs. XVII e XVI a.C., correspondendo ao período "Castellucciano". Por volta da Idade do Bronze tardia reconhece-se, através da presença, na "Cittadella", de cerâmica apenínica, a chegada de populações da Península Itálica, confirmando a tradição antiga sobre os Morgetes. Finalmente, cabanas da Idade do Ferro ocupam vários espaços na "Cittadella", encerrando o período de povoamento pré-grego na região.

Pouco antes da metade do séc.VI a.C. é perceptivel uma profunda transformação na área da "Cittadella" com a inserção de um estabelecimento de tipo claramente urbano. Há uma mudança radical nos achados tanto no que diz respeito às concepções arquitetônicas quanto ao caráter dos artefatos: o material indígena cede lugar ao material importado da Grécia e das cidades gregas da costa oriental e meridional da Sicília. Neste periodo registram-se como edificações: uma longa e estreita capela sem identificação do culto, uma série de fundações possivelmente associadas a habitações e um pequeno hieron dedicado a Deméter e Perséfone. Desde o final do séc. VI e início do V a.C., a "Cittadella" era provida de muros de defesa próprios.

À conquista da pólis localizada na "Cittadella", por Ducétio, seguiu-se um período de abandono da área e subsequente fundação de uma "segunda cidade" no platô de Serra Orlando (PR XII:313), por volta da metade do séc. V a.C.

A ágora da nova cidade ocupa uma vasta depressão que se estende por $200 \mathrm{~m}$ de comprimento por $150 \mathrm{~m}$ de largura desenhando um retângulo cujas diagonais orientam-se no sentido N.S. e E.O. Embora o plano desta segunda pólis date provavelmente da década de Ducétio (459450 a.C.) os edifícios construidos a partir deste traçado são muito mais recentes. Resultam do mais importante momento na história de Morgantina, no séc. III, quando a cidade tornouse uma espécie de "posto avançado" do reino de Hieron II de Siracusa. Nesta época a população atingiu o seu maior número, as casas e os santuários ocuparam a maior extensão dentro dos muros $\mathrm{e}$ o imenso espaço da ágora foi preenchido por amplos edificios públicos (ver fig.2).

A datação do momento de implantação do plano ortogonal, na metade do séc. V o situa como um dos mais antigos na Sicília central. Os limites da ágora eram definidos por ladeiras, denominadas colinas Este e Oeste, e, paralelamente às suas margens, foram traçadas as ruas retilineas do projeto urbanistico ortogonal. Assim, o traçado regular e uniforme - apenas a rua El escapa à regra - compreendia ruas e quarteirões que se estendiam, a partir da área central, em direção leste e oeste.

Por volta do séc. IV a.C., o terreno em declive destinado à ágora foi estruturado em dois grandes terraços, cujas fronteiras eram definidas por edificios públicos. O nivel superior configura-se como uma praça, circundada, em três lados, por stoai cobertas, sendo que a maior delas nunca foi terminada (Fig. 2, q, $\mathrm{x}, \mathrm{y}$ ); a ágora inferior tem armazéns públicos como limites (Fig. 2, d, g). Os espaços remanescentes eram preenchidos por vários tipos de edificações como uma "casa de águas" e uma pequena stoa na ágora superior (Fig. 2, p, w), um santuário e séries de lojas na inferior (Fig. 2, n, m, f).

Uma série de degraus monumentais separava os dois níveis da ágora. Serviam tanto como muro de arrimo para previnir a erosão da área superior quanto para acomodar a população por ocasião de grandes assembléias populares, atuando como um ekklesiasterion (Fig. 2). Esta construção constitui, para M. Bell, a "estrutura-chave" que articula todo o conjunto arquitetônico-urbanistico da ágora.

O teatro ocupa o lado sul ocidental da ágora inferior utilizando o declive natural da colina circundante. A este deste edificio e em estreita $e$ significativa relação com ele encontra-se um pequeno santuário com um recinto interno circular que dispõe de um altar.

Ainda no interior da ágora foram encontrados um naiskos pequeno com um altar e outros dois ou três altares isolados. Quando a área assumiu a configuração final estas construções foram abandonadas, à exceção de um dos altares que foi incorporado ao Macellum datado do séc. II. (Fig.2, y).

Um santuário dedicado aos deuses do mundo subterrâneo, e que foi o único a subsistir 
também elegantes casas com peristilo, nas colinas que cercam a ágora e os santuários dedicados a Deméter e Perséfone encontramse repletos de belas estatuetas de terracota.

A extensão do plano ortogonal para as áreas adjacentes ao platô inicialmente ocupado indicam uma população crescente e uma economia em expansão.

Em sintese, as escavações comprovam que Morgantina é essencialmente uma cidade do séc. III a.C. e, em especial, da época de Hieron II de Siracusa (circa 305-215 a.C.). Este tirano notabilizou-se não só por implementar um significativo avanço econômico como também por incentivar, com afinco, as artes em geral.

Morgantina vivenciou, juntamente com Siracusa e outras cidades gregas da Sicília, o intenso dinamismo cultural próprio da chamada "era hieroniana". As fontes escritas registraram em especial o florescimento da metalurgia: em 217 a.C. Hieron enviou a Roma uma Niké "em ouro" (T. Lívio 22, 37, 5); juntos Hieron e Gelon enviaram a Rodes caldeirões em prata (Políbio 5, 88,5 ). As escavações recuperaram muitos exemplares de vasilhame em bronze em Siracusa e jóias, tanto nesta cidade quanto em Morgantina. A pequena plástica em terracota evidencia também uma larga produção de peças de alto nível datadas do inicio do periodo helenístico.

Ao final do século III a.C., no entanto, a situação atestada pelos registros arqueológicos é desoladora: áreas habitacionais abandonadas, santuários dedicados a Deméter e Perséfone saqueados e abandonados, a produção de terracotas interrompida. A razão de toda esta destruição é simples: enquanto aliada de Roma como Siracusa - a cidade prosperou, não obstante a conjuntura difícil da Primeira Guerra Púnica. Quando, no entanto, a preocupação com as vicissitudes romanas na Segunda Guerra Púnica e as dissenções internas que se seguiram à morte de Hieron II levaram Siracusa e as cidades suas aliadas a apoiarem Cartago, a reação romana foi exemplar e imediata. Em 211 a.C. Morgantina foi capturada pelos romanos e, a seguir, oferecida como prêmio de guerra a um grupo de mercenários hispanos. Os principais eventos que pontuaram a vida da Sicília de 214 a 212 a.C. foram relatados por Livio $(24,36,10$ e $26,14,17)$.

Alguns autores (Sjöqvist, 1960c:58 e White, 1964:270) têm proposto que o culto de Deméter e Perséfone estaria envolvido em um movimento de resistência aos romanos ao final do terceiro século, o que justificaria o tratamento brutal dado aos seus santuários quando da derrota de Morgantina.

As únicas referências literárias a Morgantina no séc. II referem-se às revoltas de escravos de 139-131 e 104-101 a.C.; para a segunda metade deste século o registro arqueológico aponta a cunhagem de séries de moedas de bronze com a legenda HISPANORVM e a construção de uma grande edificação servindo como mercado no nivel superior da ágora.

O santuário das divindades ctônias situado no patamar inferior da ágora parece ter sido o único centro religioso que sobreviveu até o séc. II. O achado de placas de chumbo com inscrições dedicatórias às divindades infernais permitem supor o seu caráter ctônio, mas nenhuma relação com o culto original alí realizado, pode ser estabelecida.

Neste periodo ocorre a reocupação das ricas habitaçðes localizadas nas colinas circundantes da ágora, mas a intensa subdivisão dos espaços internos sugere o contínuo processo de empobrecimento iniciado a partir da chegada dos hispanos.

Os administradores romanos provavelmente aceleraram o declínio de Morgantina, como o fizeram com outras cidades siciliotas. Cícero (Verr. 2.3. 103) inclui os Murgentini entre os civitate decumanae submetidos à voracidade de Verres. As ecavações indicam que o sítio sofreu um lento processo de decadência até o abandono total da área no início da era cristã. Escrevendo no final do século I a.C., Estrabão $(16,2,4)$ referese a Morgantina como uma cidade que não mais existia.

\section{História urbanistica da cidade}

A identificação da atual localidade de Serra Orlando com a antiga cidade greco-sícula de Morgantina constituiu um dos primeiros e significaticos resultados das escavações americanas na área. Erim (1958:79-90) em sua tese de doutorado, em 1957, defendia essa associação que foi definitivamente confirmada com o achado de uma inscrição no teatro da cidade.

As sucessivas e sistemáticas campanhas de escavações propiciaram o conhecimento da vida 
de Morgantina desde as épocas mais recuadas. Assim, E. Sjöqvist (1962b:52-68) descreve as mais antigas fases de ocupação do sítio, a partir do exame de evidências provenientes da área da "Cittadella" e de uma pequena extensão no platô de Serra Orlando. Nesta região foi encontrado abundante material e vestígios de cabanas datadas dos sécs. XVII e XVI a.C., correspondendo ao período "Castellucciano". Por volta da Idade do Bronze tardia reconhece-se, através da presença, na "Cittadella", de cerâmica apeninica, a chegada de populações da Península Itálica, confirmando a tradição antiga sobre os Morgetes. Finalmente, cabanas da Idade do Ferro ocupam vários espaços na "Cittadella", encerrando o período de povoamento pré-grego na região.

Pouco antes da metade do séc.VI a.C. é perceptivel uma profunda transformação na área da "Cittadella" com a inserção de um estabelecimento de tipo claramente urbano. Há uma mudança radical nos achados tanto no que diz respeito às concepções arquitetônicas quanto ao caráter dos artefatos: o material indígena cede lugar ao material importado da Grécia e das cidades gregas da costa oriental e meridional da Sicília. Neste periodo registram-se como edificações: uma longa e estreita capela sem identificação do culto, uma série de fundações possivelmente associadas a habitações e um pequeno hieron dedicado a Deméter e Perséfone. Desde o final do séc. VI e início do V a.C., a "Cittadella" era provida de muros de defesa próprios.

À conquista da pólis localizada na "Cittadella", por Ducétio, seguiu-se um periodo de abandono da área e subsequente fundação de uma "segunda cidade" no platô de Serra Orlando (PR XII:313), por volta da metade do séc. V a.C.

A ágora da nova cidade ocupa uma vasta depressão que se estende por $200 \mathrm{~m}$ de comprimento por $150 \mathrm{~m}$ de largura desenhando um retângulo cujas diagonais orientam-se no sentido N.S. e E.O. Embora o plano desta segunda pólis date provavelmente da década de Ducétio (459450 a.C.) os edifícios construídos a partir deste traçado são muito mais recentes. Resultam do mais importante momento na história de Morgantina, no séc. III, quando a cidade tornouse uma espécie de "posto avançado" do reino de Hieron II de Siracusa. Nesta época a população atingiu o seu maior número, as casas e os santuários ocuparam a maior extensão dentro dos muros e o imenso espaço da ágora foi preenchido por amplos edifícios públicos (ver fig.2).

A datação do momento de implantação do plano ortogonal, na metade do séc. $\mathrm{V}$ o situa como um dos mais antigos na Sicília central. Os limites da ágora eram definidos por ladeiras, denominadas colinas Este e Oeste, e, paralelamente às suas margens, foram traçadas as ruas retilineas do projeto urbanistico ortogonal. Assim, o traçado regular e uniforme - apenas a rua El escapa à regra - compreendia ruas e quarteirões que se estendiam, a partir da área central, em direção leste e oeste.

Por volta do séc. IV a.C., o terreno em declive destinado à ágora foi estruturado em dois grandes terraços, cujas fronteiras eram definidas por edificios públicos. O nível superior configura-se como uma praça, circundada, em três lados, por stoai cobertas, sendo que a maior delas nunca foi terminada (Fig. 2, q, $\mathrm{x}, \mathrm{y}$ ); a ágora inferior tem armazéns públicos como limites (Fig. 2, d, g). Os espaços remanescentes eram preenchidos por vários tipos de edificações como uma "casa de águas" e uma pequena stoa na ágora superior (Fig. 2, p, w), um santuário e séries de lojas na inferior (Fig. 2, n, m, f).

Uma série de degraus monumentais separava os dois níveis da ágora. Serviam tanto como muro de arrimo para previnir a erosão da área superior quanto para acomodar a população por ocasião de grandes assembléias populares, atuando como um ekklesiasterion (Fig. 2). Esta construção constitui, para M. Bell, a "estrutura-chave" que articula todo o conjunto arquitetônico-urbanistico da ágora.

O teatro ocupa o lado sul ocidental da ágora inferior utilizando o declive natural da colina circundante. A este deste edifício e em estreila e significativa relação com ele encontra-se um pequeno santuário com um recinto intemo circular que dispõe de um altar.

Ainda no interior da ágora foram encontrados um naiskos pequeno com um altar $\mathrm{e}$ outros dois ou três altares isolados. Quando a área assumiu a configuração final estas construções foram abandonadas, à exceção de um dos altares que foi incorporado ao Macellum datado do séc. II. (Fig.2, y).

Um santuário dedicado aos deuses do mundo subterrâneo, e que foi o único a subsistir 
à destruição de 211 a.C., integrava também o espaço da ágora e comportava um altar circular e compartimentos variados destinados ao pessoal envolvido no culto. (Fig. 2, z). Em Morgantina não foram encontrados templos propriamente ditos, mas, ao menos quatro capelas dedicadas a Deméter e Perséfone e caracterizadas pela presença de um adyton, e uma enorme quantidade de estatuetas de terracota.

A ágora era circundada por várias residências ricas ornamentadas com pisos em mosaico: a casa de Ganymedes, do Oficial, da Cisterna.

As necrópoles estavam localizadas fora da cidade: a mais antiga, datada dos sécs. VI e V, situa-se próximo da "Cittadella" e apresenta tumbas escavadas nas rochas; uma segunda área funerária data de 330 a 210 a.C. aproximadamente e foi implantada junto do muro Oeste; a mais recente, do séc. II, está localizada a cerca de 100 $m$ da cidade em direção também oeste.

Os muros que circundavam o perimetro total da cidade foram reconstruídos muitas vezes, em vários momentos, o que dificulta o conhecimento que se possa ter a seu respeito.

Pouco se conhece da chora de Morgantina. É certo que foi uma cidade agrícola como demonstram os achados de prensas para óleo e vinho e apetrechos para o preparo de grãos similares aos documentados em muitas outras cidades do interior da Sicilia. As escavações, no entanto, abrangeram a área central do estabelecimento e não os seus arredores.

A ágora de Morgantina apresenta, hoje, após as escavações americanas, um quadro sequencial de ocupações, distribuído por seis períodos principais, que cobrem quase cinco séculos (sécs. $\mathrm{V}$ a I a.C.). Os resultados permitem que se redimensione o papel de Morgantina no conjunto de cidades que foram integradas à área de influência siracusana, sob o domínio de Hieron II (269 - 215 a.C.). Assim, o programa urbanístico-arquitetônico implantado nos periodos $\mathrm{II}$ (segundo quartel do séc. III) e IV (segunda metade do séc. III a 211 a.C.) significa um grande esforço empreendedor no sentido de dotar a cidade de uma infraestrutura básica e eficiente no que diz respeito à circulação de pessoas e armazenamento de gêneros alimentícios o que permite supor uma certa proeminência em relação às póleis vizinhas, certamente em função de sua localização estratégica.
Desta feita, datam do periodo III: a stoa E e terraços; os degraus centrais; naiskoi; são provavelmente deste momento $o$ início da construção do armazém este (Fig. 2, d) e da stoa $\mathrm{N}$ (Fig. 2, $\mathrm{x}$ ); o Bouleuterion e a stoa dórica (Fig. 1, u, v). Durante o periodo IV foram construidos: a stoa $\mathrm{W}, \mathrm{o}$ anexo da stoa $\mathrm{E}$ (Prytaneon) e terraço (Fig. 1, s); foram ampliados os degraus centrais $\mathrm{e}$ o armazém este. Possivelmente incluem-se também nesta época a reconstrução da skene do teatro e das defesas da ágora em sua porção sudeste, incluindo a torre e proteichisma (Fig. 2, c).

Para Malcolm Bell, as construções da época de Hieron II atestam, de um lado o apego a uma tradição arquitetônica claramente grega, indicando, tanto em termos de posicionamento quanto das linhas, uma "enorme consciência da arquitetura urbana das póleis gregas como conhecemos de numerosos outro sitios mediterrânicos" (PR XII:339). Ao mesmo tempo, nuances de elementos siciliotas incorporados aproximam os edifícios de Morgantina de modelos oriundos de Siracusa: é o caso das stoai e dos armazéns públicos (PR XII:339-340, fig. 33).

É impossível finalizar esta rápida sintese sobre os conhecimentos novos que as escavações de Morgantina apresentam, no campo da urbanística e arquitetura, sem mencionar alguns resultados do trabalho arqueológico na "Fountain House" (Fig.2, p). Observou-se que a água armazenada em dois grandes reservatórios, inicialmente com capacidade para cerca de $\mathbf{5 2 . 0 0 0}$ dm3, provinha de uma fonte localizada nos arredores e da captação da água pluvial por meio do próprio telhado do edifício e da stoa vizinha. Junto dos canais que conduziam a água, da fonte à casa, foram encontrados objetos votivos variados: lamparinas, bustos e pinakes em terracota, sendo que nestes aparecem representações das Ninfas. Este achado comprova a presença, em Morgantina de cultos possivelmente assemelhados aos do santuário rupestre de Agrigento (Siracusano, 1983:53-75) e que vêm sendo associados à religião de Deméter e Perséfone.

A "Casa das águas", desde a sua construção, datada de aprox. 275-250 a.C, sofreu sucessivas reformulações (PR XII: figs, 22, 23, 24, 25 e 29) permanecendo, no entanto, por quase duzentos anos como uma fonte pública de água destinada a atender às necessidades da ágora. Os contínuos 
esforços no intuito de adequá-la a esta função, à medida que a demanda crescia, significam, para M.Bell que a provisão de água era considerada um encargo público característico de uma pólis. A este propósito, inclusive, cita Pausânias (10.4.1) para quem, a ausência de edifícios públicos, teatro, ágora e krene ("casa das águas") constituiria impedimento suficiente para o reconhecimento de uma cidade como pólis.

\section{SÉRIE MORGANTINA STUDIES}

BELL, M. Morgantina Studies I: The Terracottas. Princeton, Princeton University Press, 1981. Pp. 266, pls. 150.

O primeiro volume da série Morgantina Studies é dedicado à produção coroplástica do sítio e apresenta aos especialistas um conjunto inédito de documentos oriundos das escavações da Universidade de Princeton, de uma vasta coleção do Museu Nacional de Siracusa e de um pequeno acervo do Museu de Palermo. Estas duas últimas coleções resultaram de doações e aquisições de proprietários rurais da região. $O$ catálogo abrange 1.331 terracotas em 958 entradas; constam dele todas as peças de Palermo, a maioria das de Siracusa, bem como os exemplares recuperados em dezesseis campanhas arqueológicas (de 1955 a 1972) selecionadas em função de suas condições fisicas (p. 115).

$\mathrm{O}$ trabalho de M. Bell, no entanto, é muito mais do que uma catálogo comentado. Trata-se, isto sim, de uma obra fundamental sobre a estruturação da religião grega em uma pólis colonial, revelando empréstimos diretos e adequações e/ou reformulações que a nova conjuntura histórico-cultural propunha, como um desafio, aos recém-chegados.

Nesta perspectiva, precedem o catálogo uma "Introdução e esboço histórico", quatro capítulos que analisam os principais conjuntos de terracotas dos periodos arcaico e clássico inicial; clássico tardio; helenístico inicial e helenístico-tardio e um longo e importante capítulo denominado "Terracotas votivas" (pp. 81 a 111) voltado para a interpretação religiosa das imagens em terracota.

O próprio Catálogo é introduzido por uma exposição objetiva que discute questões básicas relativas aos artefatos descritos: critérios de seleção e apresentação; locais de origem/ proveniência; técnica de fabricação. A temática iconográfica norteia a classificação das terracotas, que, ao mesmo tempo, são agrupadas em dois conjuntos cronologicamente distintos: um, composto de peças dos periodos arcaico e clássico inicial (n's. 1 a 55) e outro que inclui os exemplares relativos aos periodos mais recentes ( $n^{\circ} \mathrm{s}$. 56 a 968). Merece destaque a inclusão - rara em obras do gênero - de uma "listagem de contextos" que permite, ao especialista não presente à escavação, uma visão geral do relacionamento dos vários artefatos, ao momento do achado. Nas palavras de $\mathrm{M}$. Bell, trata-se de arrolar "as evidências circunstanciais concer-nentes à descoberta das peças catalogadas" (p.3), e isto é feito através da definição exata do local de achado, com comentários a respeito da situação do estrato e datação pertinente, descrição e quantificação dos artefatos associados. $\mathrm{O}$ autor indica também a publicação relativa a cada contexto, em geral os Preliminary Reports.

A contextualização das terracotas permite que se estabeleçam os santuários, as necrópoles e as habitações como os principais locais de achado em Morgantina. Os dados coletados por M.Bell permitiriam um estudo quantitativocomparativo da relação "temática-iconográfica/ local de achado" nos vários períodos, mas o autor não se propõe a isto. De todo modo, algumas interessantes associações devem ser destacadas: assim, ao contrário do que ocorre em outros sítios siciliotas como Gela, os prótomos femininos de terracota têm significativa frequência como oferenda funerária nas sepulturas em câmara, de uso coletivo, datadas do séc. VI e até do V a.C. (cf. p. 257, tumba 28, enterramento); diferentemente também da situação da grande maioria dos sítios arcaicos, as terracotas não são registradas nos vários naskoi escavados e as poucas peças recuperadas em Morgantina neste periodo provêm de niveis de habitação e sepulturas (pp. 9-10).

Estes poucos exemplos demonstram como o conhecimento se amplia quando o estudo de um artefato se insere em uma abordagem sistemática de um sítio e, por outro lado, como a presença desta 
listagem de contextos torna-se uma verdadeiro "banco de dados" maximizando o nível de informações que os artefatos estão aptos a fornecer a outros pesquisadores da área que não participaram das escavações.

Logo na "Introdução" (p. 3) M. Bell sinaliza o direcionamento e o propósito de seu trabalho: de um lado, ressalvando a inexistência de um estudo geral sobre as terracotas de um sítio na Sicília, argumenta a respeito da importância do seu estudo para a discussão de questões básicas relacionadas à produção e circulação deste artefato em contextos siciliotas; por outro lado, estabelece, de imediato as dimensões da terracota enquanto fonte para o conhecimento do culto de Perséfone em Morgantina. Mais adiante, reconhece que, dada a ausência de fontes escritas sobre a religião em Morgantina, as terracotas constituem o mais completo conjunto de evidências sobre a natureza dos cultos documentados nos santuários e completa: "Cada um desses objetos chegou a um santuário mediante um ato de devoção. Se os seus "sujeitos" puderem ser identificados, poderemos conhecer mais não somente sobre as terracotas, mais também, logicamente, sobre os sentimentos religiosos dos homens e mulheres que os dedicaram" (p. 81). E reside justamente ai, na busca da identificação das imagens, o maior esforço de $\mathrm{M}$. Bell enquanto um verdadeiro historiador da religião. $O$ resultado é a elaboração de um modelo centrado na figura de "uma" Perséfone específica - em essência, a esposa de Hades, como em Locres -, ao redor da qual gravitam uma divindade masculina (Hades?), outras figuras divinas ou mitológicas como Ártemis, as Ninfas, Eros e, finalmente, um séquito de serviçais do culto (sacerdotisas?) ou fiéis.

Os quatro capítulos iniciais analisam a produção coroplástica de Morgantina destacando questões básicas tais como: os focos de origem dos vários tipos e grupos, visando distinguir centros criadores e/ou grandes produtores de áreas periféricas, receptoras; problemas estilísticos e de cronologia e identificação da representação iconográfica.

Ao contrário do que normalmente é observado em "Catálogos" de terracota ou mesmo de outros artefatos, M. Bell preocupa-se sistematicamente em estabelecer paralelos históricos que permitam uma inserção objetiva da documentação no quadro conjuntural instável da Sicília. Dai sua afirmativa de que "a história das terracotas de Morgantina está inscrita na história do sítio" (p. 4). Esta história aponta para um periodo de calmaria politica durante o reinado de Hieron II e justamente nesta época M.Bell avalia como o apogeu da coroplastia em Morgantina: grosso modo sécs. IV-III a.C., correspondendo aos períodos Clássico tardio e Helenistico inicial. Desta feita, a contribuição maior que as terracotas de Morgantina poderão propiciar ao conhecimento das terracotas siciliotas circunscreve-se a esta época que é tratada em dois longos e densos capítulos (Cap.II e III; pp. 22 a 40 e 41 a 73).

Destacaremos, a seguir, algumas questões que deverão exemplificar a abordagem assumida pelo autor ao adotar o referencial histórico como vetor da análise dos artefatos e, ao mesmo tempo, inserir o documento material na dimensão que the é própria, neste caso, a esfera religiosa.

Ao inscrever a evolução da coroplastia em Morgantina no quadro histórico siciliota, M. Bell reafirma a hegemonia política de Siracusa, que, estendendo-se ao campo das artes visuais (p. 22) a partir do séc. IV, acaba por anular a vigente independência cultural das cidades-estados. Assim, após a destruição imposta pelos cartagineses a cidades como Gela, Selinonte, Agrigento, Camarina que se constituiam em núcleos criativos no campo da coroplastia, os arquétipos oriundos de Siracusa direcionam a produção de Morgantina bem como de outras cidades da Sicilia. Em resumo, as terracotas documentam o crescimento politico de uma cidade: Siracusa.

M. Bell identifica também, através dos estratos arqueológicos, o crescimento das estatuetas de terracota no período de intensa prosperidade econômica que se segue ao apoio dado pelos cidadãos de Morgantina a Agátocles, quando de seu retorno ao poder, em Siracusa (317 a.C.). Neste sentido, explica-se a fundação de santuários dedicados a Deméter e Perséfone na cidade em sintonia com um amplo processo de revitalização destes cultos em outras localidades da Sicília (p.24). A origem deste movimento teria sido a política de repovoamento estabelecida por Timoleonte por volta de 340330 a.C. que estimulou paralelamente a vida religiosa e criou uma demanda em relação às terracotas; a prosperidade da agricultura, por sua vez, forneceu aos homens as condições materiais 
de realizar oferendas aos deuses (p.24).

A preocupação de $\mathrm{M}$. Bell com a interpretação da temática iconográfica, etapa indispensável na sua busca do sentido religioso das terracotas o leva a adotar um procedimento pouco usual nesta área: o exercício da analogia entre diferentes suportes de imagens. Neste sentido ao analisar os bustos femininos, oferenda extremamente popular na segunda metade do séc.IV, o autor volta-se para outros artefatos como moedas, pinakes (de Locres,especialmente) e mesmo até representaçס̃es figuradas em vasos cerâmicos ápulos, para estabelecer paralelos temáticos que permitam uma melhor compreensão de suas imagens no quadro da religião grega colonial (pp.27 a 33).

A mesma estratégia é empregada no estudo de uma categoria de terracotas de dimensões surpreendentes (de 35 a $60 \mathrm{~cm}$ de altura) e que representam uma figura feminina de pé do tipo conhecido como "opfernde Götter". Os paralelos aqui são estabelecidos com a grande estatuária e as moedas (p.45).

Vale lembrar que M. Bell participou intensamente das escavações de Morgantina, tendo sido, inclusive, responsável pelos trabalhos em algumas campanhas e deverá publicar os resultados referentes à urbanística da cidade no que diz respeito à ágora. Assim, compreende-se a familiaridade com que ele trata vários tipos de documentos e a visão abrangente da problemática histórica do sítio, em consonância com a vida religiosa de Morgantina.

Ao final destas considerações acreditamos que o primeiro volume da série Morgantina Studies espelha as preocupações dos arqueólogos que vêm conduzindo o projeto de exploração deste sítio siciliota: o estudo de um caso - Morgantina como parâmetro para a discussão de temas básicos recorrentes em todos os núcleos coloniais. Assim, as terracotas de Morgantina propiciam balizas cronológicas, estilísticas, técnicas que poderão nortear o enfoque da coroplastia siciliota tão carente de estudos sistemáticos e aprofundados bem como de publicações completas sobre sítios escavados. Em uma perspectiva mais ampla, a própria religião colonial foi muito enriquecida pelo estabelecimento de uma visão abrangente e integrada da vida cultual, fundamentada em fontes documentais de diversas naturezas mas abordadas criticamente.
BUTTREY, T.V.; ERIM, K.T.; GROVES, T.D. e HOLLOWAY, R.R. Morgantina Studies II: The Coins. Princeton, Princeton University Press, 1989. Pp.XX + 245, pls.49.

O propósito básico deste volume de Morgantina Studies foi o de apresentar o catálogo comentado dos achados monetários durante as escavações realizadas de 1955 a 1981. É preciso dizer que a obra ultrapassa, e de muito, o mero registro dos achados pois inclui além do catálogo, um estudo aprofundado da oficina monetária de Morgantina, comentários individualizados sobre cada achado mais relevante e a relação de cada achado com a estratigrafia do sítio. Em três apêndices ao final do volume, apresenta ainda os artigos originais de Erim e Buttrey sobre a atribuição do nome Morgantina a Serra Orlando a partir dos achados de moedas HISPANORVM e sobre a data da criação do denário romano. Dois pontos que, sem sombra de dúvida, constituem contribuições espetaculares para a história da Arqueologia e da Numismática siciliota e romana. Trata-se de uma obra única, tanto pela qualidade dos achados monetários de Morgantina quanto pela maneira detalhada escolhida para a apresentação do material. Com efeito, são muito raras ou mesmo inexistentes as publicações extensivas como esta sobre todos os achados monetários de uma escavação. Como afirma a conservadora chefe de moedas gregas da American Numismatic Society, Carmen Amold-Biucchi: "This is the largest group of excavated coins ever published from an Italian site" (Amold Biucchi, 1992:188-9).

$\mathrm{Na}$ primeira parte do livro, K. T. Erim, apresenta um estudo das moedas fabricadas na oficina monetária de Morgantina. Trata-se de uma versão ampliada pelo autor do artigo que havia publicado nas Atti del IV Convegno del Centro Internazionale di Studi Numismatici de 1975 (vide Bibliografia ) e revista por E. Jauzems para esta edição. É preciso dizer que as moedas de Morgantina não são por nada comuns ou abundantes, tendo em vista a importância menor da cidade em relação às outras colônias gregas do litoral da Sicilia. Por isso mesmo mereceram - injustamente - menos atenção dos especialistas.

Este estudo de Erim aborda todas as moedas que podem ter sido cunhadas em Morgantina, inserindo aquelas encontradas durante as escavações no contexto maior dos exemplares de 
coleções, conhecidos através de catálogos, exposições, etc..

Na primeira parte, o Autor elabora um estudo de cunho das moedas mais antigas de Morgantina, de prata e de bronze, datando-as dos séculos V e IV a. C. Como cidade interiorana, sua cunhagem teve início em época posterior à de outras colônias gregas e foi bastante esporádica e modesta: emitiu basicamente moedas de prata de denominações menores como a litra e a litra e $1 / 4$ (os tetradracmas são raríssimos) e de bronze, já na segunda metade do século IV a.C.

Em seguida, o Autor apresenta - mais suscintamente - as raras emissões EIKEAIRTAN, aceitando a atribuição à Morgantina aventada por Sjöqvist (1960c:53-63). Talvez esta falta de uma confirmação mais segura do local de emissão destas moedas (ainda que autores importantes como Manganaro a aceitem; ver 1981-82:37-54) tenha feito o Autor tratá-las tão brevemente.

Finalmente, são apresentadas as moedas HISPANORVM, encontradas abundantemente durante as escavações (um total de 706 peças) e cuja cunhagem marcaria o final das atividades da oficina monetária de Morgantina.

Com relação a estas moedas, no estudo das quais o Autor se detém demoradamente, é indispensável considerar alguns pontos básicos:

a. Morgantina é o local onde foi encontrada a maior quantidade dessas peças, de todos os tipos e cunhos. Mesmo no caso das moedas de coleção, quando possuem registro de proveniência, este indica as imediações de Serra Orlando.

b. Há inúmeras fontes que atestam a presença de mercenários hispanos lutando em solo da Sicilia desde o século V a.C. Entretanto, Lívio assinala explicitamente que durante a II Guerra Púnica, mercenários espanhóis teriam recebido dos romanos a cidade de Morgantina como recompensa por sua lealdade (T. Lívio, XXVI, 21, 17).

c. Do ponto de vista da estratigrafia, e de associação com contextos arqueológicos específicos em Morgantina, as moedas HISPANORVM devem ser datadas de 137 a 84 a. C.

O estudo das moedas HISPANORVM permitiu a Erim algumas conclusões históricas e numismáticas muito importantes. Em primeiro lugar, a identificação de Serra Orlando com
Morgantina, hipótese já assinalada com muito fundamento logo após as primeiras campanhas de escavação em publicação de 1958 (Erim, 1958: 79-90). Publicação esta reeditada, aliás, neste volume de Morgantina Studies, com leves modificações (pp.201-214). É preciso dizer também que mais tarde a descoberta de uma inscrição monumental no teatro, permitiu confirmar esta identificação de sorte que hoje ela é aceita por praticamente todos os especialistas (PR VII:164).

Em seguida, é mérito do autor ter organizado e ter dado sentido a um grupo não pequeno de moedas que permanecia sem estudo e "solto", descontextualizado. A associação destas moedas HISPANORVM à oficina de Morgantina permitiu, sem dúvida, a compreensão da importância desses grupos mercenários na Sicília e a interferência que tinham no desenrolar dos acontecimentos. A comparação com os Mamertinos, mercenários estabelecidos em Messana durante o século III a.C. e que também fabricaram moedas, é, nesse sentido, enriquecedora.

Este estudo, tão aprofundado, das moedas HISPANORVM, tem, no entanto, uma limitação: como explicar o hiato entre a ocupação de Morgantina pelos hispanos em 211 a.C. e a emissão do primeiro grupo de moedas em 137 a.C.? Tanto tempo ficaram os hispanos em Morgantina? Por que custaram a bater moedas? São perguntas que, ainda que não comprometam o resultado final desta pesquisa, continuam merecendo atenção dos especialistas que procuram ainda respostas satisfatórias. Maria Caccamo Caltabiano, por exemplo, através de um estudo metrológico, comparativo, dessas moedas, chegou à conclusão de que são frações do sistema romano do as sextantal devendo ser datadas, portanto, do final do século III e início do II a.C. (Caccamo-Caltabiano, 1985:159-69). Nesse caso, a aproximação com a fonte textual é clara, ocorrendo um distanciamento grande em relação ao dado fornecido pelos achados arqueológicos. Esta dificuldade poderá eventualmente ser sanada com a publicação dos estudos sistemáticos de outros materiais arqueológicos de Morgantina como a cerâmica, os materiais de construção, etc., etc..

Neste estudo sobre a oficina monetária de Morgantina, Erim manipula com habilidade os três tipos de fontes que tem à sua disposição: os 
textos, as moedas, os contextos arqueológicos. É preciso dizer que a definição dos grupos de moedas e da sua cronologia é elaborada através do uso criterioso de elementos como iconografia, peso metal, associados à estratigrafia do sítio e às informações trazidas pelas fontes textuais.

Este trabalho de articulação das fontes disponiveis se completa na segunda e na terceira partes do volume. O catálogo detalhado de cada uma das 9.898 moedas identificadas em Morgantina foi montado por Buttrey, Erim, Holloway, Groves e Visonà. Peças isoladas ou grupos inteiros de moedas mereceram anotações destes especialistas, compiladas entre as pp. 135 e 155. Aqui, cada um em sua área, anota o que há de importante sobre o peso das moedas, sobre a iconografia, sobre a atribuição, etc.. Algumas anotações são mais' sucintas, outras mais detalhadas, chegando inclusive a enriquecer a polêmica com relação à cronologia de moedas e da estratigrafia do sítio. Tal é o caso da longa nota "363, 366-369" sobre as numerosíssimas peças Posidão/tridente (muitas vezes partidas ao meio), de Hieron II. Estas moedas foram estudadas detalhadamente por R.R. Holloway (1960:65-73). Os vários grupos foram definidos a partir do tamanho do disco monetário e da iconografia e o estudo metrológico levou o Autor a concluir que as peças cortadas serviram como numerário fracional durante a ocupação interina romana da Sicília, durante a Segunda Guerra Púnica. Foi inclusive possível identificar nessas peças as reduções ponderais ocorridas no bronze romano durante a guerra, fornecendo subsídios importantes para a datação da introdução do sistema romano do denário. A nota traz, além das conclusões anteriores tiradas no artigo de 1960, as posições mais recentes - como as de Crawford, Thomsen, Marchetti - e o debate que estas moedas suscitaram a partir dos achados de Morgantina. Debate que continua ainda, do ponto de vista da arqueologia do sítio, uma vez que M. Bell, o último escavador, apresenta uma cronologia mais antiga para algumas estruturas (especificamente as escadarias da ágora) associadas a achados deste tipo de moedas, propondo, portanto, para elas, uma datação mais alta (PRXII :330). Neste mesmo Report (pp.3402) Holloway responde e contra-argumenta a posição de Bell. Mais uma vez estamos diante do desafio: em que medida pode uma moeda datar uma camada estratigráfica ou, vice-versa, em que medida é a camada estratigráfica que data a moeda? A transparência do debate e a maneira escolhida por estes arqueólogos para dispor dos resultados da escavação para o público é realmente notável e deve ser tomada como mais um exemplo - entre tantos - do espírito científico desta equipe.

Na terceira parte do volume são apresentados os contextos arqueológicos nos quais cada moeda ou grupo de moedas foi encontrado. A descrição do achado, com referência ao catálogo e às notas aparece aqui precedida por uma breve informação sobre o local de achado: estrato, templo, praça, residência, pote, espalhado, etc.. Referência ao Report original onde $\mathrm{o}$ achado foi publicado pela primeira vez é igualmente incluída. Neste ponto talvez tivesse sido útil a apresentação de uma descrição um pouco mais extensa do local de achado, de modo a facilitar a contextualização sem necessariamente ter-se que recorrer às outras publicações. Outro ponto que ficou sem maiores explicações nesta parte do volume é o porquê de apenas $18 \%$ (1798) do total de moedas identificadas terem sido associadas ao contexto de achado. Por tudo o que já foi dito até agora, não resta a menor dúvida da "revolução" operada na história numismática da Sicília pela contextualização de apenas estas 1798 moedas; entretanto, seria desejável que o leitor fosse colocado a par das razões que os editores tiveram para excluir da publicação os dados referentes aos contextos estratigráficos das demais moedas.

De toda forma, é inegável que o catálogo, as notas e as associações arqueológicas constituem um valiosíssimo instrumento de trabalho para o estudioso de moedas especificamente ou da arqueologia e história da Sicília.

Finalmente, é preciso fazer referência aqui aos três apêndices colocados no término do volume, todos os três reedições de artigos já publicados em periódicos especializados. No primeiro deles, $\mathrm{K}$. Erim faz o estudo das moedas HISPANORVM que levou à identificação de Morgantina e sobre o qual já falamos acima. Os outros dois, de autoria de T. V. Buttrey, discutem a fundo os achados de moedas romanas em Morgantina e fixam em definitivo a data da introdução do denário romano nos anos que vão de 215 a 211 a.C., em plena Segunda Guerra Púnica (pp.215-219 e 220-226). 
Foi durante o Congresso Intemacional de Numismática em Roma (1961) que Buttrey apresentou ao público especializado um estudo sobre as moedas romanas encontradas em Morgantina: moedas de prata e ouro, claramente pertencentes às primeiríssimas fases da cunhagem do sistema do denário foram encontradas seladas em camadas de destruição por fogo, sob telhas do teto, em contexto (cerâmica, terracota, jóias, etc.) arqueológico perfeitamente datado do momento durante a Segunda Guerra Púnica em que Morgantina fora castigada por trair Roma e passar para o lado cartaginês em 214 ou 211 a.C.

$\mathrm{O}$ fato de a publicação sistemática dos achados monetários ter demorado tanto tempo para aparecer, suscitou dúvidas entre muitos estudiosos que não aceitaram estas conclusões. Buttrey, em 1979, publicou, então, um outro artigo (Buttrey, 1979:149-57; reeditado neste volume) no qual apresenta novamente e com mais detalhes os dados de Morgantina, rebatendo assim os seus críticos.

$\mathrm{Na}$ verdade, um achado tão importante não poderia ter esperado mais de vinte anos para receber uma publicação sistemática e aprofundada. A nosso ver, mesmo com todas as justificativas do mundo, esta é a grande crítica que se pode fazer com relação a este volume.

Em termos de conteúdo, no entanto, pouco pode ser modificado. Ao contrário, estudos mais recentes, achados mais recentes, têm vindo confirmar as conclusões destas escavações. Neste sentido devem ser vistos os longos estudos de Thomsen ou de Marchetti ou ainda as publicações sobre o tesouro achado em Enna (Burnett, 1983:10-11) ou sobre outros dois tesouros provenientes das redondezas de
Morgantina (Walker, 1984:269-288). Todos estes estudos permitem um refinamento maior da classificação e da cronologia dessas primeiras moedas romanas achadas nas escavações de Morgantina. A importância da Sicília e da Segunda Guerra Púnica para a consolidação do sistema do denário romano, bem como a data da sua introdução em 214 a.C. foram também confirmadas pelos estudos de M. Caccamo Caltabiano sobre um tesouro de moedas romanas de ouro encontrado em 1987 durante escavações arqueológicas em Agrigento (Caccamo Caltabiano, 1991:58).

Considerando a enorme contribuição dada pelas escavações em Morgantina para o conhecimento do início do sistema do denário, alguns especialistas esperavam que este volume publicado em 1989, incluísse novas informações, ou dados mais atualizados sobre achados correlatos - o que de fato não acontece (Hersch, 1992: 189). Esta seja talvez uma critica pertinente, pois a inclusão dessas novas descobertas - como as que citamos acima ou ainda de tantas outras, jogariam uma nova luz sobre os achados de Morgantina, valorizando e fundamentando melhor as conclusões já estabelecidas na década de sessenta.

Ainda assim, reafirmamos que o volume II de Morgantina Studies, deve ser considerado hoje um instrumento precioso de trabalho que além das contribuições pontuais sobre temas muito precisos, permite que o Leitor construa uma visão global da fabricação e movimentação de moedas em uma cidade grega do interior da Sicilia. Fornece ainda os elementos indispensáveis para que o especialista estude aspectos importantes da economia desta região.

Esta é uma proeza que bem poucas equipes de arqueólogos têm realizado...

\section{BIBLIOGRAFIA}

Os títulos bibliográficos, relativos aos PRELIMINARY REPORTS e às PUBLICAÇÕES SOBRE A DOCUMENTAÇÃO ARQUEOLÓGICA DE MORGANTINA, são apresentados em ordem cronológica, com o objetivo de demonstrar o volume de publicações que acompanha a evolução das escavações arqueológicas em Morgantina. 


\section{PRELIMINARY REPORTS (PR)}

STILLWELL, R. e SJŌQVIST,E. (1957) Excavations at Serra Orlando. Preliminary Report. AJA, 61:151-159.

SJOQVIST,E. (1958) Excavations at Serra Orlando (Morgantina). Preliminary Report II. AJA, 62:155-164 (com um apêndice de G. Stamires sobre uma inscrição grega incisa em um pithos de argila).

STILLWELL,R (1959) Excavations at Serra Orlando 1958. Preliminary Report III. AJA, 63:167-173.

SJO̊QVIST,E. (1960a) Excavations at Morgantina (Serra Orlando) 1959. Preliminary Report IV. $A J A, 64: 125$ 135.

STILLWELL,E. (1961) Excavations at Morgantina (Serra Orlando) 1960. Preliminary Report V. AJA, 65:277281.

SJÖQVIST,E. (1962a) Excavations at Morgantina (Serra Orlando) 1961. Preliminary Report VI. AJA, 66:135143.
STILLWELL, R. (1963) Excavations at Morgantina (Serra Orlando) 1962. Preliminary Report VII . AJA, 67:163171.

SJŌQVIST,E. (1964) Excavations at Morgantina (Serra Orlando) 1963.Preliminary Report VIII. AJA, 68:137147.

STILLWELL,R. (1967) Excavations at Morgantina (Serra Orlando) 1966. Preliminary Report DX. AJA, 71:245-250.

ALLEN,H.L. (1970) Excavations at Morgantina (Serra Orlando), 1967-69. Preliminary Report X.AJA, 74:359.

ALLEN,H.L. (1974) Excavations at Morgantina (Serra Orlando), 1970-1972: Preliminary Report XI. AJA, 78:361-382.

BELL III, M. (1988) Excavations at Morgantina, 19801985: Preliminary Report XII. AJA, 92:313-342.

SJŐQVIST,E. (1958) Timoleonte e Morgantina, Kokalos, 6:107-118.

\section{PUBLICAÇÕES SOBRE A DOCUMENTAÇÃO ARQUEOLÓGICA DE MORGANTINA}

ERIM,K.T. (1958) Morgantina. AJA, 62:79-90.

SJŐQVIST,E. (1959) Archaeological Notes. Morgantina: Hellenistic Inkstands. $A J A, 63: 275-277$.

SMITH,M. (1959) Archaeological Notes. On the New Inscription from Serra Orlando. AJA, 63:183-184.

SJÖQVIST, E. (1960b) Archaeological Notes. Morgantina: Hellenistic Medicine Bottles. AJA, 64:78-83

PHILLIPS, Jr., K.M. 1960 Subject and technique in Hellenistic - Roman Mosaics, a Ganymede Mosaic from Sicily. $A B$ 42:243-60

HOLLOWAY, R.R. (1960) Numismatic Notes from Morgantina II. Half Coins of Hieron II in the Monetary System of Roman Sicily. ANSMN, 9:65-73.

HOLLOWAY, R.R. (1960-61) Monete provenienti dagli scavi di Morgantina e già attribute a Hiempsal II. AIIN 7-8:35-37.

SJOQVIST, E. (1960c) Numismatic Notes from Morgantina

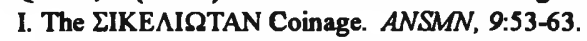

- . (1960d) Perchè Morgantina? RendLinc., 15:296 e ss.

- (1962b) I greci a Morgantina. Kokalos, 8:52-68.

STILLWELL, R. (1964-65) The theater of Morgantina. Kokalos, 10-11:579-88.

BUTTREY, T.V. (1965) The Morgantina Excavations and the Date of the Roman Denarius. Atti del Congresso Internazionale di Numismatica 1961. Roma:261-67.

HOLLOWAY, R.R. (1965) Monetary circulation in Central Sicily to the Reign of Augustus as Documented by the Morgantina Excavations. Atti del Congresso Internazionale di Numismatica 1961. Roma:135-50.

HOLLOWAY, R.R. (1969-70) The Bronze Coinage of the Third Syracusan Democracy (344-316 B.C.). AIIN 16
17:129-42.

ALLEN, H.L. (1972/73) Per una definizione della facies preistorica di Morgantina; l'età del ferro. Kokalos 1819:146-160

BUTTREY,T.V. (1973) The Morgantina Gold Hoard and the Coinage of Hicetas. NC, s.7, v.13:1-17.

ERIM,K.T. (1975) La zecca di Morgantina. Le emissioni dei centri Siculi fino all 'epoca di Timoleonte. AIIN, 20 , supplemento:67-76.

KOLB, F. (1975) Agora und theatron in Morgantina. Kokalos, 8:52-68.

BELL,M. (1977) Le terracotte votive del culto di Persefone a Morgantina. Cronache di Archeologia e di Storia dell'arte, 16:140-147

NARBERS,N. (1979) Archaeological Notes. Ten Lead Tabellae from Morgantina. AJA, 83:463-464.

BUTTREY,T.V. (1979) Morgantina and the Denarius. NAC, 8:149-157.

HOLLOWAY, R.R. (1979) The Bronze coinage of Agathocles. Greek Archaeology and Numismatics: Essays in Honor of Margaret Thompson. Wetteren : 87-97.

CROUCH,D.P. (1984) The Hellenistic Water System of Morgantina, Sicily: Contributions to the History of Urbanization. $A J A, 88: 353-365$.

BELL, M. (1984 - 85) Scavi recenti nell'agora di Morgantina. Kokalos, 30-31:40-65

TSAKIRGIS,B. (1989) The Decorated Pavements of Morgantina I: The Mosaics. A/A, 93:395-416.

TSAKIRGIS,B. (1990) The Decorated Pavements of Morgantina II: The Opus Signimum. AJA, 94:425-443.

NEILS,J. (1992) The Morgantina Phormiskos. AJA, 96:225235. 


\section{BIBLIOGRAFIA DE REFERÊNCIA}

AMMERKMAN, R.M. (1984). Resenha de Mongantina Studies I: The Terracotas by Bell, M., 1981. AJA, 88:422-423.

ARNOLD-BIUCCHI, C. (1992) Resenha de Morgantina Studies II: The Coins by Erim, K.T. and alii, 1989. AJA, 96:188-190.

BLANTON, R. (1970) Monte Albán. Settlement Patterns at the Ancient Zapotec Capital. N. York, Academic Press.

BURNETT, A.M. (1983) The Enna Hoard and the Silver Coinage of the Syracusan Democracy. SNR, 62:10-11.

CACCAMO CALTABIANO, M. (1985) Sulla cronologia e la metrologia delle serie Hispanorum. NAC, 14:159-69.

CACCAMO CALTABLANO, M. (1991) Il tesoretto di oro "marziale" da Agrigento, 1987. Xle. Congrès International de Numismatique. Resumes des Communications. Bruxelles :58.

CARANDINI, A et alii (1985) Settefinestre. Una villa schiavistica nell 'Etruria romana. Modena, Ed. Panini.

CHILDS, W. A P. (1979) Morgantina, Past and Future. AJA, 83:377-379.

COARELLI, F. e TORELLI, M. (1988) Morgantina. Guide Archeologiche Laterza. Sicilia. Bari, Laterza : 188-201.

FIORENTINI, G. (1980-81) Kokalos, 26/27:589-98.

GABBA,E. e VALLET, G. (1980) Morgantina. La Sicilia Antica, Vol. I, 3 Roma, (3 vol.) : 731-738.

GALLO, L. (1992) La Sicilia occidentale e l'approvvigionamento cerealicolo di Roma. ASNP, s.III, v.XXII,
2:365-399.

HERSCH, C.A. (1992) At last, Morgantina. Reviewing Buttrey, Erim, Groves, Holloway, Morgantina Studies 2: The Coins. American Journal of Numismatics, 3-4 :187-194.

MANGANARO, G. (1989) Case e terra a Kamarina e Morgantina nel III-II sec. A.C.. PP, XZIV:189-216.

MARCHETTI, P. (1978) Histoire economique et monétaire de la deuxième guerre punique. Bruxelas.

MERCATOR, G. (1589) Italiae Sclavoniae et Graeciae tabulae geographicae - Siciliae Regnum. Duisburg.

RIZZO, G.E. (1946) Monete Greche della Sicilia. Nápoles.

SIRACUSANO, A. (1983) Il santuario rupestre di Agrigento. Sikelika 2:53-75.

STILLWELL, R. (1976) Morgantina. The Princeton Encyclopedia of Classical Sites. Princeton University Press:594-95.

STOCKLI, W.E. (1975) Bemerkungen zur Chronologie von Victoriat, Denar, Quinar und Sesterz. JNG, 25:73-90.

THOMSEN, R. (1957-61)Early Roman Coinage. A study of Chronology. Copenhaguen.

WALKER, A.S. (1984) Some Hoards from Sicily and a Carthaginian Issue of the Second Punic War. Festschrift fur Leo Mildenberg, Wetteren, 1984:269-88.

WHITE,D. (1964). Demeter's sicilian cult as a political instrument. Greek, Roman and Byzantine Studies, S, 4:260-279. 